\title{
Age-related changes in the surface pheromones of the wasp Mischocyttarus consimilis (Hymenoptera: Vespidae)
}

\author{
E.F. Neves ${ }^{1}$, L.H.C. Andrade ${ }^{2}$, Y.R. Súarez ${ }^{2}$, S.M. Lima ${ }^{2}$ and \\ W.F. Antonialli-Junior ${ }^{1,2}$
}

${ }^{1}$ Programa de Pós-Graduação em Entomologia e Conservação da Biodiversidade, Universidade Federal da Grande Dourados, Dourados, MS, Brasil

${ }^{2}$ Laboratório de Ecologia,

Centro Integrado de Analise e Monitoramento Ambiental,

Universidade Estadual de Mato Grosso do Sul, Dourados, MS, Brasil

Correspondence: E.F. Neves

E-mail: erika_snakes@yahoo.com.br

Genet. Mol. Res. 11 (3): 1891-1898 (2012)

Received November 3, 2011

Accepted January 5, 2012

Published July 19, 2012

DOI http://dx.doi.org/10.4238/2012.July.19.8

\begin{abstract}
One of the most important attributes that allowed the evolution and maintenance of sociality in insects is their ability to distinguish members of their own colonies. The capacity for individual recognition in social insects is mediated by chemical signals that are acquired soon after the adult emerges, and vary according to the tasks performed by individuals in their colonies. We determined the time when adults of the wasp Mischocyttarus consimilis acquire the chemical signature of their colonies, as well as the variation in the cuticular hydrocarbon profiles of the exoskeleton of individuals, according to their functions in the colony. The method used was Fourier transform infrared photoacoustic spectroscopy directly on the gaster of each individual. Young wasps take three to four days to acquire the colony's chemical signature, with a small change on the fifth day, when the cuticular hydrocarbon profile of the workers is more similar to that of the queens than that of the males, probably because they are of
\end{abstract}


the same sex, but primarily because of the similarity of tasks executed by these two groups of females in the colonies.

Key words: Colony signature; Division of labor; Behavior repertoire; Colony identity

\section{INTRODUCTION}

In insect societies, reproductive division of labor plays an important role in the maintenance of colony structure; workers cooperate with their queens, which are generally morphologically different. Reproduction and an elaborate communication system coordinate worker behavior (Wilson, 1971). One of the conditions that favor the evolution and maintenance of this system is the ability to distinguish nestmates (Hamilton, 1987).

To carry out multiple tasks in colonies, social insects have developed mechanisms of chemical communication used (Ferreira-Caliman et al., 2007). These compounds, termed pheromones, act on the receiving individual, as physiological triggers of specific behavioral reactions (Leal, 2005).

Cuticular hydrocarbons are members of a class of volatile compounds known as "surface pheromones". These pheromones are important for the social insects, allowing the recognition of members of the same species, nests, and members of different castes. Generally, the pheromones appear to be absorbed by the body surface and are detected by other insects, over small distances or by direct contact (Abdalla et al., 2003). These compounds are usually related to the identification of the individual's role in the colony, in other words, which caste it belongs to, which individuals are genetically related, what their function is in the colony, and other behavioral questions (Singer et al., 1998).

Several investigators have demonstrated that recognition of individual functions exercised in colonies of social insects is mediated by chemical signals, which are acquired soon after the insects emerge. Adults of the wasp Mischocyttarus mexicanus accumulate an odor with increasing age after emerging; acceptance of individuals of other colonies diminishes as the wasps age (Gamboa et al., 1996).

Another important factor for recognition signals, well documented by Espelie et al. (1990), is the odor of the insects' own nest material, which contains hydrocarbon-rich compounds that are capable of being transferred between individuals and are used as a way to recognize the colony. In social wasps, the recognition processes are mediated by the odor of the nest surface, which is covered by cuticular hydrocarbons produced by the colony's members. The nest odor is used as a reference by wasps when they learn to distinguish the odor of their colony, and as a mode of emergence recognition (Gamboa et al., 1996).

Several techniques have been used to evaluate the profiles of cuticular hydrocarbons in social insects. One of the most recently developed is optical spectroscopy, by Fourier transform infrared photoacoustic spectroscopy (FTIR-PAS) (Antonialli Jr. et al., 2007, 2008).

We determined the time when adults of the wasp Mischocyttarus consimilis acquire the chemical signature of their colonies, as well as the changes in the cuticular hydrocarbon profiles of the exoskeleton of these individuals, according to their functions in their colonies.

\section{MATERIAL AND METHODS}

To determine when the chemical signature of the colony is acquired by adults, 10 colonies of M. consimilis nesting on the campus of Universidade Federal da Grande Dourados, in 
Dourados, Mato Grosso do Sul $\left(22^{\circ} 13^{\prime} 16^{\prime \prime S}, 54^{\circ} 48^{\prime} 20^{\prime}\right.$ "W) were studied. For the monitoring of ages, all recently emerged individuals from these colonies were marked with non-toxic ink on the thorax. Ten individuals collected from 10 different colonies, of each age from recently emerged to 5 days old, based on the behavior-transfer results of Panek et al. (2001), were used.

To evaluate the differences in the cuticular hydrocarbon profiles of workers, queens and males, six colonies from three different areas were included. These were two colonies from a rural area of Bodoquena (20 32 ' 19 'S,$\left.-56^{\circ} 42^{\prime} 54^{\prime \prime} \mathrm{W}\right)$, two from the campus in Dourados, and two from an urban area in the municipal district of Batayporã (22 $\left.13^{\prime} 16^{\prime \prime} \mathrm{S}, 54^{\circ} 48^{\prime} 20^{\prime \prime} \mathrm{W}\right)$. Colonies from different populations were evaluated in order to obtain more reliable results for the average cuticular hydrocarbon profile of this species.

All the insects used for both analyses were anesthetized, killed, and preserved by freezing. This procedure avoided the use of a fixative or chemical preservative that could react with chemical elements of the cuticle. For the analyses of the cuticular hydrocarbon profile, the gaster was extracted from each individual. According to Cuviller-Hot et al. (2001) this area of the body has the greatest cuticular hydrocarbon concentration.

The analysis technique was optical spectroscopy, by FTIR-PAS, according to Antonialli Jr. et al. (2007, 2008). This method has not customarily been used for this type of study, but has proven to be reliable.

The FTIR-PAS technique measures the radiation absorbed by a sample. It has advantages for application to materials of great fragility, such as biological materials, because the low-intensity radiation does not destroy the sample. Furthermore, FTIR-PAS can be used to analyze very small samples (Greene et al., 1992). FTIR-PAS uses the infrared spectrum from 400 to $4000 \mathrm{~cm}^{-1}$ (Silverstein et al., 2000; Skoog et al., 2002). This area is sensitive to the vibrations and rotations of molecular chemical groups, so it can identify and distinguish molecular radicals and some kinds of chemical bonds in certain samples, the most advantageous aspect of this technique (Smith, 1999).

To minimize humidity, which can affect the spectrum reading, the samples were placed in a vacuum oven for $48 \mathrm{~h}$. Then, each gaster was placed on a support in the photoacoustic cell, and purged with helium gas. The spectrum was obtained for each abdomen, for the mean of 64 spectra with a resolution of $8 \mathrm{~cm}^{-1}$. The absorption lines between 400 and $4000 \mathrm{~cm}^{-1}$ were separated; these are related to vibrations of hydrocarbons, which provide the information to analyze.

All the data were evaluated by stepwise discriminant analysis, which can reveal the group of variables that best explains the groups evaluated in case of a difference, which is indicated by Wilk's lambda, a measure of the difference, if any, between the groups (Quinn and Keough, 2002).

\section{RESULTS}

The spectra analyzed by FTIR-PAS showed that the significant functional groups between 400 and $4000 \mathrm{~cm}^{-1}$ were linked mainly to chitin and hydrocarbons present in the wasp cuticle (Table 1).

The discriminant analysis demonstrated that the individuals that emerged from colonies of $M$. consimilis began acquiring their chemical signature between the third and fourth day after emerging the cuticular hydrocarbon profiles differed on the fifth day (Figure 1). The first canonical root explained $73 \%$ of the results and the second $27 \%$; both together explained $100 \%$ of the results. The discriminant analysis gave a significant result (Wilks' lambda $=$ $0.005 ; \mathrm{F}=8.988 ; \mathrm{P}<0.001)$; of 18 peaks analyzed, seven were meaningful for separation of the groups (Figure 2 and Table 1). 
Table 1. Wavenumber, coefficients of the two canonical roots, functional group, and vibrations of the identified peaks in the infrared absorption spectra of the gaster of the wasps, for analysis of the effect of age.

\begin{tabular}{lcccll}
\hline Peak & Wavenumber $\left(\mathrm{cm}^{-1}\right)$ & Canonical root 1 & Canonical root 2 & Functional group & Vibration mode \\
\hline$(1)$ & 1030 & 1.746 & 0.121 & In plane C-H (benzene) & Bending \\
$(2)$ & 1157 & -2.722 & -0.224 & In plane C-H (benzene) & Bending \\
$(3)$ & 1450 & 2.141 & -0.419 & ${\mathrm{C}-\mathrm{CH}_{2} \text { and C-CH }}_{3}$ & Asymmetric bending scissors \\
$(4)$ & 1524 & -2.112 & -0.943 & $\mathrm{~N}-\mathrm{H}$ & Bending \\
$(5)$ & 1651 & 4.001 & -1.825 & $\mathrm{C}=\mathrm{O}$ & Symmetric bending \\
$(6)$ & 2634 & -1.442 & -0.015 & $\mathrm{C}-\mathrm{N}$ and N-H & Overtone bending \\
$(7)$ & 2877 & -0.178 & $\mathrm{CH}\left(\mathrm{CH}_{3}\right)$ & Symmetric stretching \\
\hline
\end{tabular}

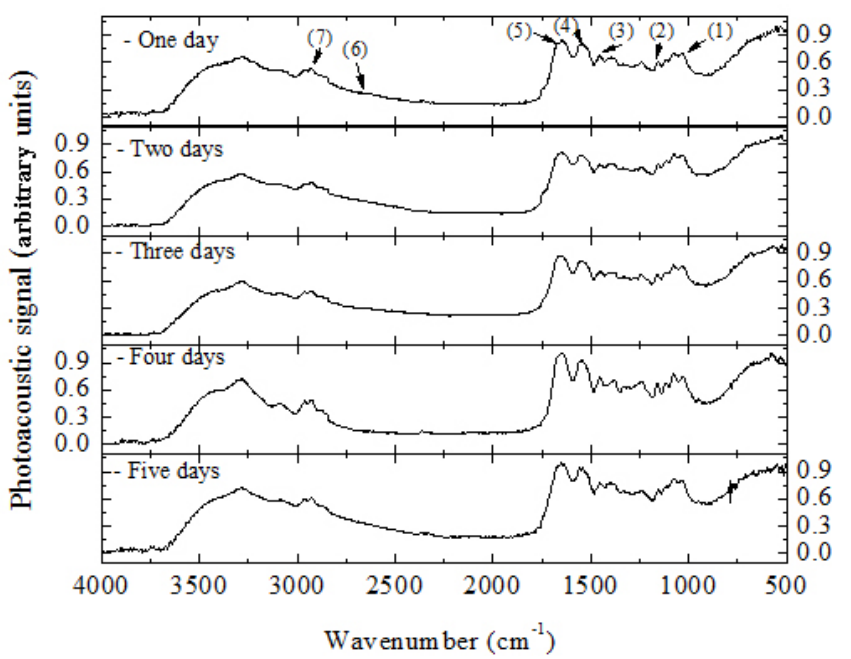

Figure 1. Mean curve for each group of absorption spectra in the mid-infrared of the gaster from different-aged specimens of Mischocyttarus consimilis, indicating the significant peaks for separation of the groups.

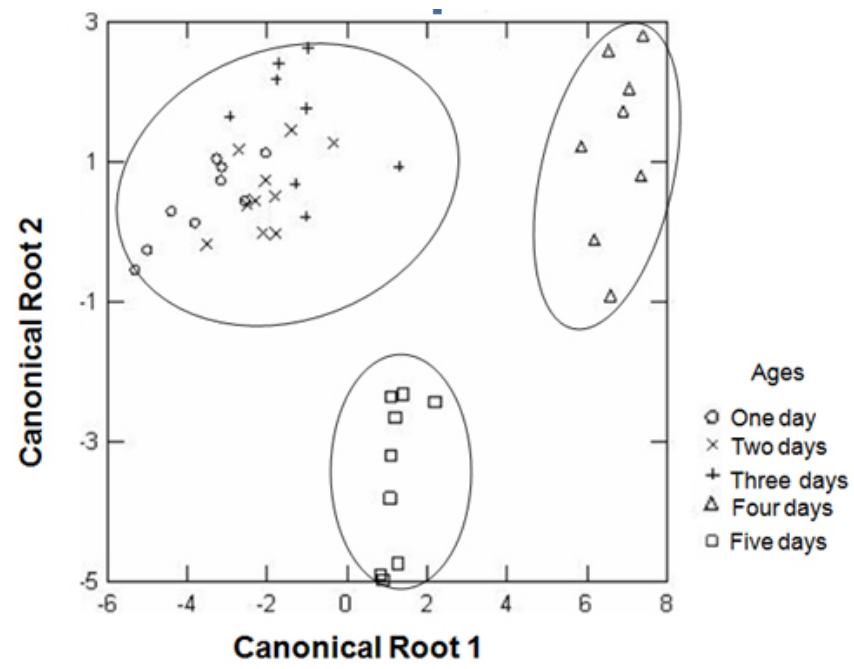

Figure 2. Dispersion diagram of the results of the discriminant analysis, showing the two canonical roots of differentiation of cuticular hydrocarbons in different-aged individuals of the wasp Mischocyttarus consimilis. 
The cuticular hydrocarbon profiles of queens, workers and males were significantly different (Figure 3). The first canonical root explained $77 \%$ of the results and the second $23 \%$, and both together explained $100 \%$ of the groups' separation (Figure 4). The most significant peaks were those with wavelengths of $667,895,953,1030,1076$, and $1115 \mathrm{~cm}^{-1}$ (Wilks' lambda $=0.034 ; \mathrm{F}$ $=12.364 ; \mathrm{P}<0.001$ ). The 667, 895 and $953 \mathrm{~cm}^{-1}$ wavelengths (see Table 2) correspond to the cuticular hydrocarbon C-H functional group with out-of-plane bend (benzene). The 1030, 1076 and $1115 \mathrm{~cm}^{-1}$ wavelengths correspond to the cuticular hydrocarbon C-H with in-plane bend (benzene).

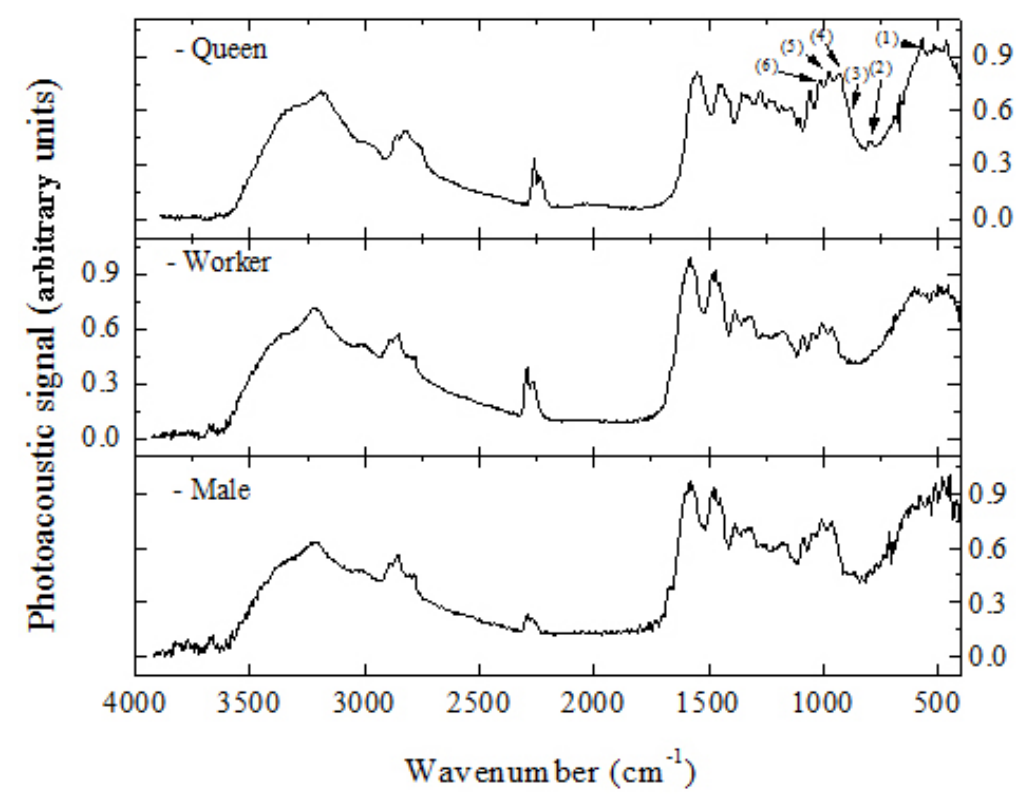

Figure 3. Mean curve for each group of absorption spectra in the mid-infrared of the gaster from workers, queens, and males of Mischocyttarus consimilis, indicating the significant peaks for separation of the groups.

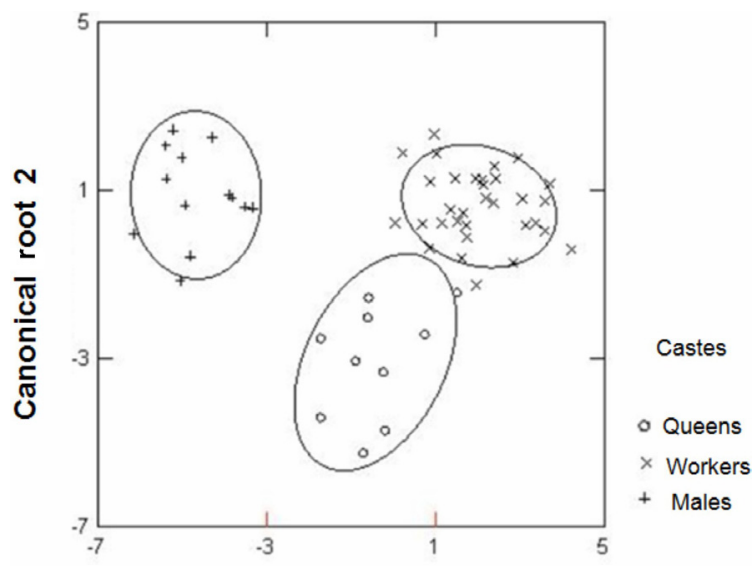

Canonical root 1

Figure 4. Dispersion diagram of the results of the discriminant analysis, showing the two canonical roots of caste and sex differentiation of the wasp Mischocyttarus consimilis. 
Table 2. Wavenumber, coefficients of the two canonical roots, functional group, and vibrations of the identified peaks in the infrared absorption spectra of the gaster of the wasps, for analysis of the effects of caste and sex.

\begin{tabular}{lccccc}
\hline Peak & Wavenumber $\left(\mathrm{cm}^{-1}\right)$ & Canonical root 1 & Canonical root 2 & Functional group & Vibration mode \\
\hline$(1)$ & 667 & 2.444 & 0.242 & Out-of-plane C-H (benzene) & Bending \\
$(2)$ & 895 & 1.099 & 0.2 & Out-of-plane C-H (benzene) & Bending \\
$(3)$ & 953 & -0.025 & -1.21 & Out-of-plane C-H (benzene) & Bending \\
$(4)$ & 1030 & -2.432 & 0.629 & In-plane C-H (benzene) & Bending \\
$(5)$ & 1076 & 2.896 & -0.291 & In-plane C-H (benzene) & Bending \\
$(6)$ & 1115 & -0.146 & 2.762 & In-plane C-H (benzene) & Bending \\
\hline
\end{tabular}

\section{DISCUSSION}

The spectra showed that significant functional groups between 400 and $4000 \mathrm{~cm}^{-1}$ were associated mainly with chitin and hydrocarbons present in the wasp cuticle (Table 1). The vibration of N-H and its fold with the wavelength around $1524 \mathrm{~cm}^{-1}$ is an important group; it was almost as intense as the $1651 \mathrm{~cm}^{-1}$ wavelength corresponding to $\mathrm{C}=\mathrm{O}$ with the stretching vibrational mode (Antonialli Jr. et al., 2007). Therefore, according to Antonialli Jr. et al. (2007) the combination of these lines can be used to diagnose chitin or secondary amides in the cuticle analyses, with the absorption line of $2634 \mathrm{~cm}^{-1}$ with bending vibration overlap. The other wavelengths $\left(2877,1450,1157\right.$, and $\left.1030 \mathrm{~cm}^{-1}\right)$ refer to hydrocarbons $(\mathrm{C}-\mathrm{H})$ found in the cuticle, varying between the vibrational mode of symmetrical stretching $\left(2877 \mathrm{~cm}^{-1}\right)$ and asymmetrical stretching of scissors $\left(1450 \mathrm{~cm}^{-1}\right)$, and that of bending with $\mathrm{C}-\mathrm{H}$ (benzene) in the plane $\left(1157\right.$ and $\left.1030 \mathrm{~cm}^{-1}\right)$. The age at which adults of $M$. consimilis acquire the colonial signature is as was described by Panek et al. (2001), who observed through the behavior of individuals transferred from different colonies, that members of colonies of the wasp Polistes fuscatus acquire their chemical signature between 48 to $72 \mathrm{~h}$ emergence as adults. After this period the individuals were aggressively expelled from the colony, demonstrating that indeed, as the days pass, the younger individuals acquire the specific chemical signature of their colony. Similarly, Arathi et al. (1997), in a study of the wasp Ropalidia marginata, reported that older wasps accepted new individuals up to five days old, after which they tended to be intolerant and aggressive, reinforcing the idea that the colony signature is acquired in the first days of life after emerging, and this profile of cuticular hydrocarbon can vary with the individual's age. This was also demonstrated in the ant Campanotus floridanus (Morel et al., 1988) and the fly Drosophila virilis (Jackson and Bartlet, 1986).

In our study, the cuticular hydrocarbon profile of workers was more similar to that of the queens than that of the males, probably because they are of the same sex, but primarily because of the similarity of the tasks executed by these two groups of females in the colonies, compared to the males. Males do not need a high concentration of hydrocarbons or a defined chemical profile, given their limited behavioral repertoire in the colony (Antonialli Jr. et al., 2007).

In many species, the cuticular hydrocarbons of adults vary according to the colony, the physiology (Blomquist et al., 1998; Lenoir et al., 1999), and between castes, as occurs in the bee Melipona bicolor (Abdalla et al., 2003) and the ant Ectatomma vizottoi (Antonialli Jr. et al., 2007). However, studies of cuticular hydrocarbon profiles in wasps are quite recent, and most of the species studied are members of the genus Polistes. In Polistes dominulus, for instance Cotoneschi et al. (2009) observed the capability of workers to distinguish the sex of their nest companions through cuticular hydrocarbons; in Polistes biglumis bimaculatus, Lo- 
renzi et al. (1997) demonstrated intra-specific recognition; in P. fuscatus, Panek et al. (2001) determined the time when the colonial signature is acquired, and Lorenzi et al. (2004) found that Polistes semenowi imitates the odor of $P$. dominulus to invade the host colony. Therefore, cuticular hydrocarbons are important compounds used for the identification of individuals in the colony (Singer et al., 1998), which can vary according to their tasks in the colony (Leal, 2005). We conclude that young individuals of $M$. consimilis take from three to four days to acquire the chemical signature of the colony, made up of the cuticular hydrocarbon profile or surface pheromones, and that this profile varies between castes and sexes, being related, as described in previous studies, to the functions performed by each individual in the colony.

\section{ACKNOWLEDGMENTS}

Research supported by FUNDECT, Universidade Estadual do Mato Grosso do Sul, for technical support and CNPq for productivity scholarships to W.F. Antonialli-Junior, L.H.C. Andrade and S.M. Lima.

\section{REFERENCES}

Abdalla FC, Jones GR, Morgan ED and da Cruz-Landim C (2003). Comparative study of the cuticular hydrocarbon composition of Melipona bicolor Lepeletier, 1836 (Hymenoptera, Meliponini) workers and queens. Genet. Mol. Res. 2: 191-199.

Antonialli WF Jr, Lima SM, Andrade LH and Suarez YR (2007). Comparative study of the cuticular hydrocarbon in queens, workers and males of Ectatomma vizottoi (Hymenoptera, Formicidae) by Fourier transform-infrared photoacoustic spectroscopy. Genet. Mol. Res. 6: 492-499.

Antonialli WF Jr, Suarez YR, Izida T, Andrade LH, et al. (2008). Intra- and interspecific variation of cuticular hydrocarbon composition in two Ectatomma species (Hymenoptera: Formicidae) based on Fourier transform infrared photoacoustic spectroscopy. Genet. Mol. Res. 7: 559-566.

Arathi HF, Shakarad M and Gadagkar R (1997). Social organization in experimentally assembled colonies of Ropalidia marginata: Comparison of introduced and natal wasps. Insectes Soc. 44: 139-146.

Blomquist GJ, Tillman JA, Mpuru S and Seybold SJ (1998). The Cuticule and Cuticular Hydrocarbons of Insects: Structure, Function, and Biochemistry. In: Pheromone Communication in Social Insect (Vander Meer RK, Breed MD, Winston ML and Espelie KE, eds.). Westview Press, Boulder, 35-54.

Cotoneschi C, Dani FR, Cervo R, Scala C, et al. (2009). Polistes dominulus (Hymenoptera, Vespidae) larvae show different cuticular patterns according to their sex: workers seem not use this chemical information. Chem. Senses 34: 195-202.

Cuvillier-Hot V, V, Cobb M, Malosse C and Peeters C (2001). Sex, age and ovarian activity affect cuticular hydrocarbons in Diacamma ceylonense, a queenless ant. J. Insect Physiol. 47: 485-493.

Espelie KE, Butz VM and Dietz A (1990). Dexydecanoate: A major component of the tergite glands of honeybee queens (Apis mellifera L.). J. Apic. Res. 29: 15-19.

Ferreira-Caliman MJ, Cabral GCP, Mateus S, Turatti ICC, et al (2007). Composição Química da Epicutícula de Operárias de Melipona Marginata (Hymenoptera, Apinae, Meliponini). Anais do VIII Congresso de Ecologia do Brasil, Sociedade de Ecologia do Brasil, Caxambu.

Gamboa GJ, Grudzier TA, Espelie KA and Bura EA (1996). Kin recognition pheromones in social wasps: Combining chemical and behavioural evidence. Anim. Behav. 51: 625-629.

Greene RV, Gordon SH, Jackson MA and Bennett GA (1992). Detection of fungal contamination in corn: potential of FTIR-PAS and DRS. J. Agric. Food Chem. 40: 1144-1149.

Hamilton WD (1987). Discrimination Nepotism: Expectable, Common, Overlooked. In: Kin Recognition in Animals (Fletcher DJC and Michener CD, eds.). Wiley, New York, 417-437.

Jackson LL and Bartlet RJ (1986). Cuticular hydrocarbons of Drosophila virilis. Comparison by age and sex. Insect Biochem. 16: 433-439.

Leal WS (2005). Pheromone Reception. In: Topics in Current Chemistry (Balzani V, Houk KN, Kessler H, Lehn JM, et al., eds.). Springer, Heidelberg, 1-36.

Lenoir A, Fresneau D, Errard C and Hefetz A (1999). The Individuality and the Colonial Identity in Ants; the Emergence of the Social Representation Concept. In: Information Processing in Social Insects (Detrain O, Deneubourg JL and 
Pasteels J, eds.). Birkhauser, Basel, 219-237.

Lorenzi MC, Bagnères AG, Clément JL and Turillazzi S (1997). Polistes biglumis bimaculatus epicuticular hydrocarbons and nestmate recognition (Hymenoptera, Vespidae). Insectes Soc. 44: 123-138.

Lorenzi MC, Cervo R, Zacchi F, Turillazzi S, et al. (2004). Dynamics of chemical mimicry in the social parasite wasp Polistes semenowi (Hymenoptera: Vespidae). Parasitology 129: 643-651.

Morel L, Vander Meer RK and Lavine BK (1988). Ontogeny of nestmate recognition cues in the red carpenter ant (Camponotus floridanus): behavioral and chemical evidence for the role of age and social experience. Behav. Ecol. Sociobiol. 22: 175-183.

Panek LM, Gamboa GJ and Espelie KE (2001). The effect of a wasp's age on its cuticular hydrocarbon profile and its tolerance by nestmate and non-nestmate conspecifics (Polistes fuscatus, Hymenoptera: Vespidae). Ethology 107: 55-63.

Quinn GP and Keough MJ (2002). Experimental Design and Data Analysis for Biologists. Cambridge University Press, Cambridge.

Silverstein RM and Webster FX (2000). Identificação Espectrométrica de Compostos Orgânicos. $6^{\mathrm{a}}$ ed. Livros Técnicos e Científicos, Rio de Janeiro.

Singer TL, Espelie KE and Gamboa GJ (1998). Nest and Nestmate Discrimination in Independent-Founding Wasps. In: Pheromone Communication in Social Insects (Vander Meer RK, Breed MD, Winston ML and Espelie EK, eds.). Westview Press, Boulder, 104-125.

Skoog DA, Holler FJ and Nieman TA (2002). Princípios de Análise Instrumental. $5^{\text {a }}$ ed. Editora Bookman, Porto Alegre. Smith BC (1999). Infrared Spectral Interpretation: A Systematic Approach. CRC Press, Boca Raton.

Wilson EO (1971). The Insect Societies. The Belknap Press of Harvard University Press, Cambridge. 